\title{
Low Cholesterol Levels Increase Symptomatic Intracranial Hemorrhage Rates After Intravenous Thrombolysis: A Multicenter Cohort Validation Study
}

\author{
Sheng-Feng Lin ${ }^{1,2}$, A-Ching Chao ${ }^{3,4}$, Han-Hwa Hu ${ }^{5,6,7}$, Ruey-Tay Lin ${ }^{3,4}$, Chih-Hung Chen ${ }^{8,9}$, Lung Chan ${ }^{7}$, \\ Huey-Juan Lin ${ }^{10}$, Yu Sun ${ }^{11}$, Yung-Yang Lin ${ }^{12}$, Po-Lin Chen ${ }^{13}$, Shinn-Kuang Lin ${ }^{14}$, Cheng-Yu Wei ${ }^{15}$, \\ Yu-Te Lin ${ }^{16}$, Jiunn-Tay Lee ${ }^{17}$, Chyi-Huey Bai ${ }^{1,18}$, on behalf of the Taiwan Thrombolytic Therapy for Acute \\ Ischemic Stroke (TTT-AIS) Study Group
}

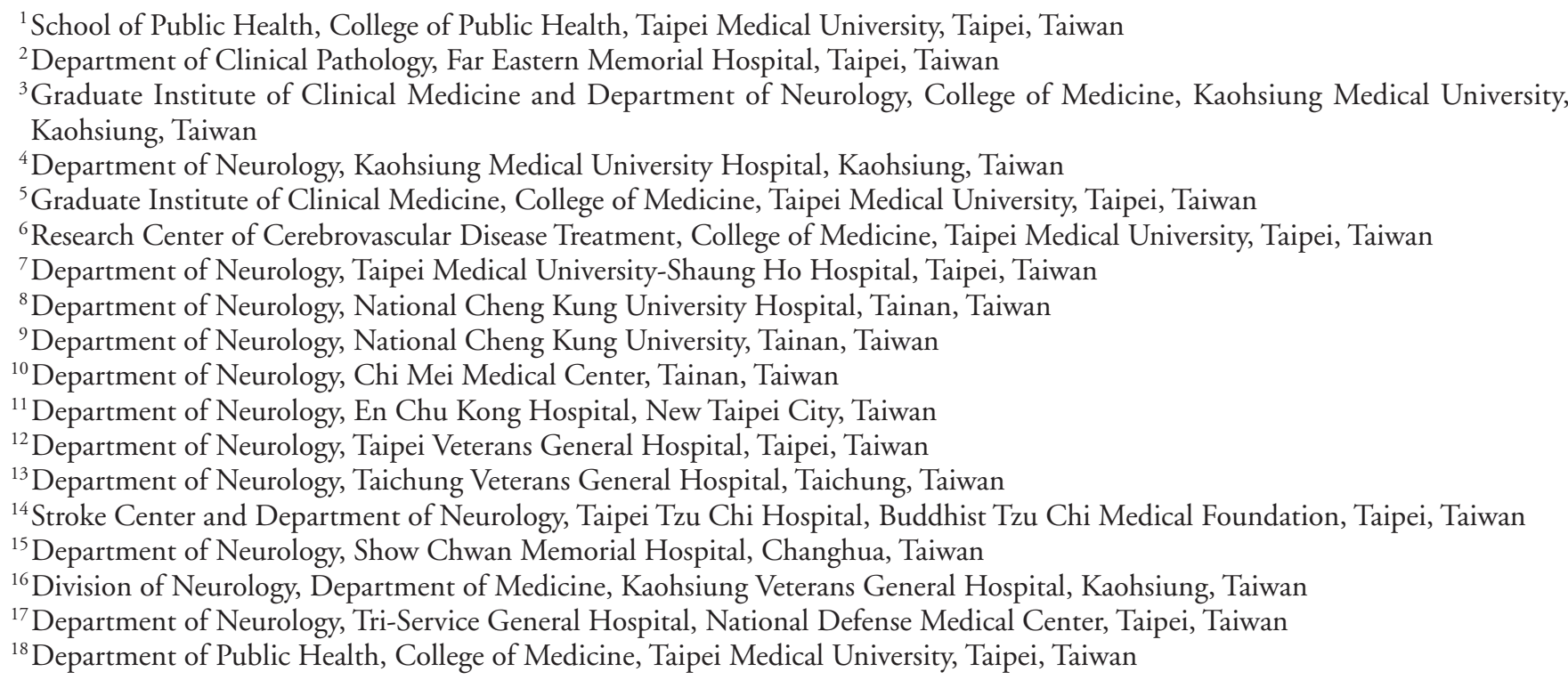

Aim: Although a lower level of non-high-density lipoprotein cholesterol (HDL-C) was reported to be inversely associated with spontaneous intracranial hemorrhage (ICH), no enough evidence has verified whether lipid profiles modify hemorrhagic transformation and functional outcomes in patients with acute ischemic treated with thrombolysis.

Methods: This multicenter cohort study included 2373 patients with acute ischemic stroke treated with intravenous thrombolysis between December 2004 and December 2016. Of these, 1845 patients were categorized into either the hyperlipidemia or non-hyperlipidemia group. Symptomatic ICH (SICH) rates within $24-36 \mathrm{~h}$ of thrombolytic onset and functional outcomes at 30 and 90 days were longitudinally surveyed. Models of predicting hemorrhagic transformation were used to validate our findings.

Results: For enrolled 1845 patients, $\mathrm{SICH}$ rates were $\geq 2$-fold reduced for the hyperlipidemia group by the NINDS (adjusted RR: 0.488 [0.281-0.846], $p=0.0106$ ), the ECASS II (adjusted RR: 0.318 [0.130-0.776], $p=0.0119$ ), and SITS-MOST standards (adjusted RR: 0.214 [0.048-0.957], $p=0.0437$ ). The favorable functional rates between the two groups were not significantly different. Lower levels of LDL-C were showed in robust association with SICH. With a cut-off LDL-C value of $<130 \mathrm{mg} / \mathrm{dL}$, new models are more robust and significant in predicting hemorrhagic transformation within $24-36 \mathrm{~h}$.

Conclusions: This study supports the strong association between reduced LDL-C and increased SICH, but not for functional outcomes in patients with acute ischemic stroke treated with intravenous thrombolysis. LDL-C level of $<130 \mathrm{mg} / \mathrm{dL}$ is supposed to a candidate marker for predicting SICH within $24-36 \mathrm{~h}$.

Key words: Stroke, Cholesterol, Low-density lipoprotein cholesterol (LDL-C), Thrombolysis, Intracranial hemorrhage 


\section{Introduction}

The level of non-high-density lipoproteins (nonHDL-C) was recognized as a possible modifying factor of intracranial hemorrhage in the multinational INTERSTROKE case-control study ${ }^{1)}$. Later, several studies found decreased total or low-density cholesterol (LDL-C) as the candidate risk factor for spontaneous intracranial hemorrhage ${ }^{2-4)}$. A 2007 study with a small sample of 104 patients provided the first evidence supporting the association between cholesterol levels and hemorrhagic transformation after intravenous (IV) thrombolysis for acute ischemic stroke ${ }^{5)}$. Nevertheless, later studies on similar topics reported inconsistent results ${ }^{5-10)}$. These studies were possibly limited by their smaller sample sizes (enrolling fewer than 500 patients ${ }^{5-7,10)}$, retrospective design ${ }^{5-8,10)}$, and missing lipid profiles in a substantial portion of patients ${ }^{9)}$. By contrast, none of the studies determined as to how much a lower level of cholesterol contributed to the increase in symptomatic intracranial hemorrhage $(\mathrm{SICH})^{5)}$ or conducted a longitudinal research on changes in the functional status in these patients. Thus, the association between decreased cholesterol levels and increased hemorrhagic transformation for acute ischemic stroke treated with IV thrombolysis is yet to be elucidated ${ }^{7,11,12)}$.

The Taiwan Thrombolytic Therapy for Acute Ischemic Stroke (TTT-AIS) registry is a nationwide cohort in Taiwan and contains longitudinal follow-up data with each patient's clinical and laboratory characteristics for 90 days ${ }^{13,14)}$. We sought to determine whether lipid profiles (1) modified the incidence of hemorrhagic transformation at $24-36 \mathrm{~h}$, and (2) altered the functional status changes in patients with acute ischemic stroke patients treated with IV thrombolysis among ethnic Chinese (i.e., Taiwanese).

\section{Methods}

\section{Design and Participants}

This multicenter cohort study included 30 hospitals in Taiwan, and the data were prospectively collected and registered in the TTT-AIS registry system. For patients with acute ischemic stroke, IV alteplase was adopted as the thrombolytic regimen at arrival within $3 \mathrm{~h}$ of stroke onset. Eligible patients fulfilled the inclusion criteria of (1) treatment with IV thrombolysis adhering to the National Institute for Neurological Disorders (NINDS) standard ${ }^{15}$ and (2) mea- surement of total cholesterol, LDL-C, HDL-C, and triglycerides (TG) in a fasting state (measured during 24-72 $\mathrm{h}$ following IV alteplase administration). Exclusion criteria for IV thrombolysis referred to the SITSMOST study standard ${ }^{16)}$. All enrolled patients with acute ischemic stroke underwent brain computed tomography (CT) on arrival at the emergency department, and another routine repeat brain CT was conducted within $24-36 \mathrm{~h}$ post IV thrombolysis. Baseline demographic data including age, sex, weight, history of hypertension, diabetes mellitus, hyperlipidemia, coronary artery disease, atrial fibrillation, alcohol consumption, blood pressure on arrival, use of antiplatelet and anticoagulant medications, baseline National Institutes of Health Stroke Scale (NIHSS) score, the alteplase dose, and time from stroke onset to IV thrombolysis were retrieved by investigators. Patients with a capacity of will signed the informed consent themselves, whereas it was signed by legal surrogate in case of patients without a capacity of will. This study was approved by the institutional review board of Kaohsiung Medical University Hospital.

\section{Outcomes Measures}

Regarding primary and secondary objectives, we evaluated the relationship between SICH and lipid profiles in two ways: (1) groups of hyperlipidemia and non-hyperlipidemia (the hyperlipidemia group was defined as total cholesterol of $\geq 200 \mathrm{mg} / \mathrm{dL}$ or LDL-C of $\geq 130 \mathrm{mg} / \mathrm{dL}$ or TG of $\geq 200 \mathrm{mg} / \mathrm{dL}$ ) and (2) total cholesterol, LDL-C, HDL-C, and TG as continuous variables $(\mathrm{mg} / \mathrm{dL})$. Patients were longitudinally surveyed at 30 and 90 days for functional outcome measurement. The modified Rankin Scale (mRS) of $0-1$ or $0-2$ was defined as favorable functional outcomes ${ }^{17)}$. SICH was defined by three criteria: (1) the National Institute of Neurological Disorders (NINDS) study standard in which any intracranial hemorrhage with deterioration of NIHSS scores of $\geq 1$ or death within $36 \mathrm{~h}^{15)}$, (2) the European Cooperative Acute Stroke Study (ECASS) II standards in which any apparently extravascular blood in the cranium with deterioration of NIHSS scores of $\geq 4$ or led to death ${ }^{18)}$, and (3) the SITS-MOST standards in which a type 2 parenchymal hemorrhage (a local or remote parenchymal intracranial hemorrhage exceeding $30 \%$ of the infarct) with clinical deterioration of NIHSS scores of $\geq 4$ or death within $36 \mathrm{~h}^{16)}$.

Address for correspondence: Chyi-Huey Bai, School of Public Health, College of Public Health, Department of Public Health, College of Medicine, Taipei Medical University, 250 Wu-Hsing Street, Taipei City 11031, Taiwan E-mail: baich@tmu.edu.tw

Received: July 26, 2018 Accepted for publication: October 9, 2018

Copyright@2019 Japan Atherosclerosis Society

This article is distributed under the terms of the latest version of CC BY-NC-SA defined by the Creative Commons Attribution License. 


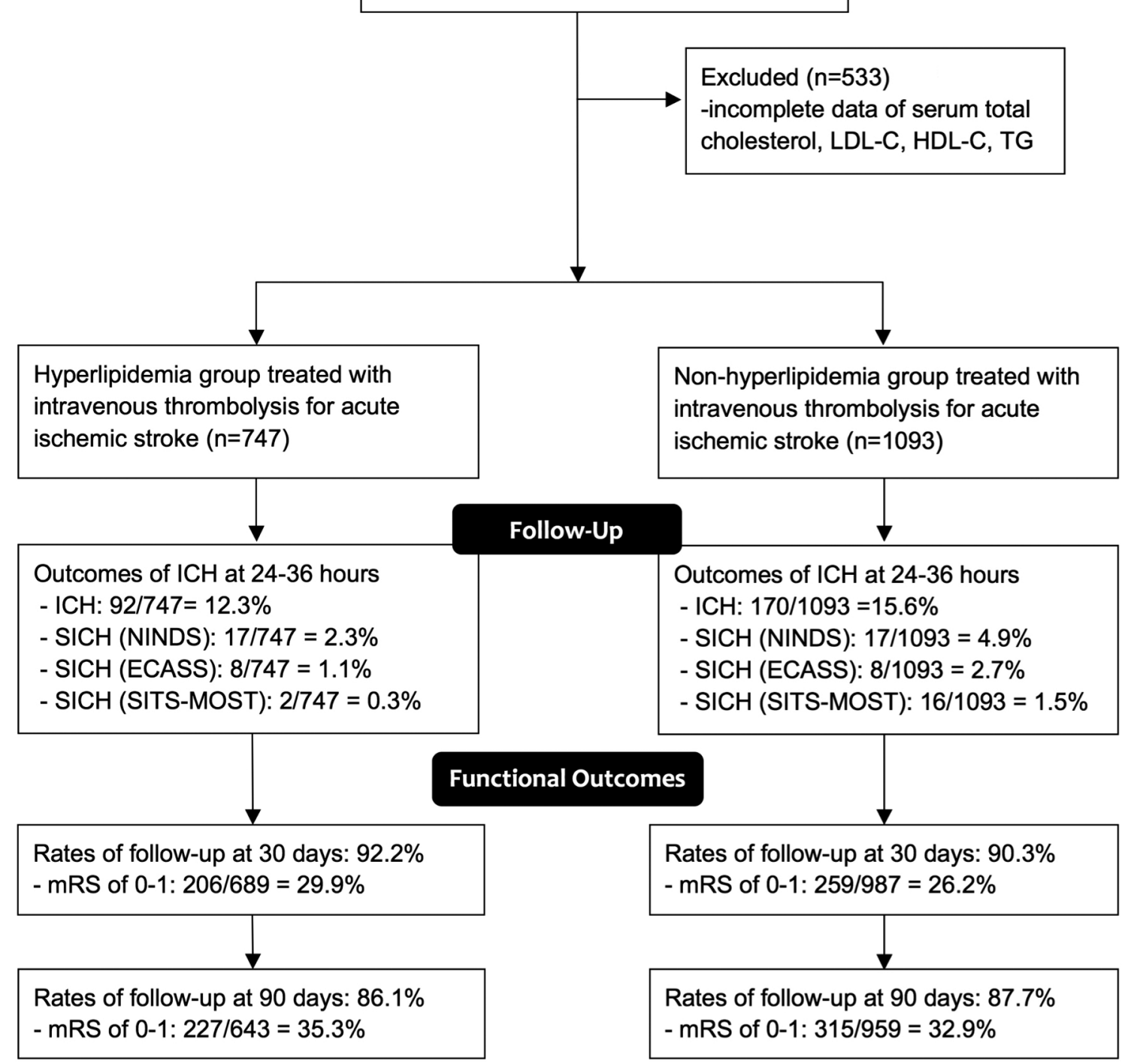

Fig. 1. The flow diagram of the research. Patients were followed up at 24-36 for intracranial hemorrhage outcomes, and at 30 and 90 days for functional outcomes.

\section{Validation Study}

As a separate part of the study, we verified which lipid profile was a candidate marker for predicting $\mathrm{SICH}$. In the current systems, there were seven validated risk-scoring models available for us to predict hemorrhagic transformation for acute ischemic stroke treated with IV thrombolysis. The candidate lipid profile was then incorporated into to the original riskscoring models, which in succession became the new model. We certified a lipid profile that was in actual association with SICH by contrasting the original and new risk-scoring models (when new models had significantly better diagnostic ability than the original one). These risk-scoring systems contained the Hemorrhage After Thrombolysis (HAT) score ${ }^{19)}$, the Safe Implementation of Thrombolysis in Stroke (SITS-SICH) score $^{20)}$, the Cucchiara score ${ }^{21)}$, the blood Sugar, Early infarct signs and hyperDense cerebral artery sign, Age, and NIHSS (SEDAN) score ${ }^{22)}$, the Stroke Prognostication using Age and National Institutes of Health Stroke Scaleand-100 (SPAN-100) index ${ }^{23)}$, the Glucose Race Age Sex Pressure Stroke Severity (GRASPS) score $^{24)}$, and the Totaled Health Risks in Vascular Events (THRIVE) score ${ }^{25)}$ (Supplemental Table 1). As a separate part of the study, we investigated the subcohort of possibly statin-naive patients. Because the 
Table 1. Demographic Characteristics of Patients with and without Hyperlipidemia

\begin{tabular}{|c|c|c|c|}
\hline Variable & $\begin{array}{l}\text { Hyperlipidemia } \\
\qquad(N=747)\end{array}$ & $\begin{array}{l}\text { No hyperlipidemia } \\
\qquad(N=1093)\end{array}$ & $p$ value \\
\hline Age (years) & $67.1 \pm 12.3$ & $69.8 \pm 13.3$ & $<0.0001^{*}$ \\
\hline Female sex; $n(\%)$ & $278(37.2 \%)$ & $388(35.5 \%)$ & 0.4517 \\
\hline \multicolumn{4}{|l|}{ Lipids (mg/dL) } \\
\hline Total cholesterol & $219.1 \pm 37.9$ & $156.5 \pm 25.6$ & $<0.0001^{*}$ \\
\hline LDL-C & $142.4 \pm 36.8$ & $91.1 \pm 24.4$ & $<0.0001^{*}$ \\
\hline HDL-C & $45.3 \pm 35.2$ & $46.7 \pm 21.5$ & 0.3296 \\
\hline TG & $162.5 \pm 110.6$ & $93.0 \pm 38.3$ & $<0.0001^{*}$ \\
\hline Body weight (kg) & $66.4 \pm 13.1$ & $64.6 \pm 12.7$ & $0.0061^{*}$ \\
\hline \multicolumn{4}{|l|}{ Medical history; $n /$ total $N(\%)$} \\
\hline Hypertension & $547 / 747(73.2 \%)$ & 786/1093 (71.9\%) & 0.5356 \\
\hline Diabetes mellitus & $237 / 747(31.7 \%)$ & $314 / 1093(28.7 \%)$ & 0.1679 \\
\hline Coronary artery disease & $88 / 747(11.8 \%)$ & $142 / 1093(13.0 \%)$ & 0.4404 \\
\hline Atrial fibrillations & $272 / 618(44.0 \%)$ & $524 / 933(56.2 \%)$ & $<0.0001^{*}$ \\
\hline Alcoholism; $n /$ total $N(\%)$ & 65/747 (8.7\%) & $79 / 1093(7.2 \%)$ & 0.2478 \\
\hline NIHSS on arrival & $12.9 \pm 7.6$ & $13.8 \pm 6.8$ & $0.0064^{*}$ \\
\hline Mean of Alteplase dose (mg/kg) & $0.81 \pm 0.13$ & $0.79 \pm 0.14$ & $0.0009^{*}$ \\
\hline Groups of Alteplase dosage & & & $0.0002^{*}$ \\
\hline Standard dose $(0.9 \mathrm{mg} / \mathrm{kg})$ & 408/747 (54.6\%) & $501 / 1093(45.8 \%)$ & \\
\hline Low dose $(<0.9 \mathrm{mg} / \mathrm{kg})$ & $339 / 747(45.4 \%)$ & $592 / 1093(54.2 \%)$ & \\
\hline \multicolumn{4}{|l|}{ Blood pressure on arrival } \\
\hline Systolic blood pressure $(\mathrm{mmHg})$ & $164.4 \pm 31.1$ & $157.6 \pm 29.6$ & $<0.0001^{*}$ \\
\hline Diastolic blood pressure $(\mathrm{mmHg})$ & $93.1 \pm 19.8$ & $89.8 \pm 19.4$ & 0.0006 \\
\hline Time to treatment (min) & $132.7 \pm 46.7$ & $131.7 \pm 46.7$ & 0.6452 \\
\hline \multicolumn{4}{|l|}{ Antithrombotic medications } \\
\hline Aspirin & $79 / 506(15.6 \%)$ & $164 / 739(22.2 \%)$ & $0.0040 *$ \\
\hline Clopidogrel & $21 / 506(4.2 \%)$ & $33 / 739(4.5 \%)$ & 0.7885 \\
\hline Ticlopidine & $6 / 506(1.2 \%)$ & $12 / 739(1.6 \%)$ & 0.5248 \\
\hline Warfarin & $19 / 506(3.8 \%)$ & $31 / 739(4.2 \%)$ & 0.6978 \\
\hline
\end{tabular}

HDL-C, high density lipoprotein-cholesterol; LDL-C, low density lipoprotein-cholesterol; NIHSS, National Institutes of Health Stroke Scale; TG, Triglycerides. Continuous variables are expressed as the mean \pm standard deviation. ${ }^{*}$ Statistically significant at $p<0.05$.

Taiwan National Health Insurance (TNHI) system had strict payment rule for statin, the subcohort was defined as exclusion of the TNHI rule (LDL-C of $\geq 130 \mathrm{mg} / \mathrm{dL}$ or total cholesterol of $\geq 200 \mathrm{mg} / \mathrm{dL}$ with diabetes mellitus or more than one of the following cardiovascular risk factors: HDL of $<40 \mathrm{mg} / \mathrm{dL}$, hypertension, male patient aged $\geq 40$ years, female menopausal patient aged $\geq 55$ years, or smoking). These results are shown in Supplemental Fig. 3 and Table 4.

\section{Statistical Analysis}

To compare the two groups, Student $t$-test was used for continuous variables and Chi-squared test was used for categorical variables. For outcomes measures, Poisson regression model was used to determine the relative risk (RR) of SICH in the $24-36 \mathrm{~h}$ of interval and Binomial regression model was used to evaluate the RR for the functional outcomes at 30 and
90 days. The multivariate regressions were applied to adjust the significantly imbalanced covariates between the hyperlipidemia and non-hyperlipidemia groups. However, covariates of the antithrombotic medications were not adjusted because of missing values in most subjects. In the validation study, receiver of operating characteristics (ROC) curves were conducted to examine the diagnostic ability of each model. The Hosmer-Lemeshow test was used to examine the model of fitness (good fitness of the model was defined as $p>0.05)$. The integrated discriminatory improvement (IDI) test was used to compare the predictive ability between the original and new models ${ }^{26,27)}$. Statistical significance was set at a $p$ value of $<0.05$. All analyses were performed using SAS 9.4 software (SAS Institute, Cary, NC, USA). 
Table 2. Analysis of the Risk of Symptomatic Intracranial Hemorrhage (SICH) for the Two Cohorts at $24-36 \mathrm{~h}$

\begin{tabular}{|c|c|c|c|c|c|c|}
\hline Variable & Hyperlipidemia & $\begin{array}{c}\text { Non- } \\
\text { hyperlipidemia }\end{array}$ & $\begin{array}{c}\mathrm{RR} \\
(95 \% \mathrm{CI})\end{array}$ & $p$ value & $\begin{array}{l}\text { Adjusted RR } \\
(95 \% \mathrm{CI})^{\dagger}\end{array}$ & $p$ value \\
\hline \multicolumn{7}{|l|}{$\mathrm{SICH}$ at $24-36 \mathrm{hrs}$} \\
\hline by NINDS standard & $17 / 747(2.28 \%)$ & $53 / 1093(4.85 \%)$ & $0.469(0.274-0.804)$ & 0.0059 & $0.509(0.277-0.933)$ & $0.0290^{*}$ \\
\hline by ECASS II standard & $8 / 747(1.07 \%)$ & $30 / 1093(2.74 \%)$ & $0.390(0.179-0.851)$ & $0.0180^{*}$ & $0.318(0.130-0.777)$ & $0.0119^{*}$ \\
\hline by SITS-MOST standard & $2 / 747(0.27 \%)$ & $16 / 1093(1.46 \%)$ & $0.183(0.042-0.795)$ & $0.0235^{*}$ & $0.216(0.048-0.966)$ & $0.0450^{*}$ \\
\hline \multicolumn{7}{|l|}{ Functional outcomes at 30 days } \\
\hline mRS of $0-1$ & $206 / 689(29.9 \%)$ & $259 / 987(26.2 \%)$ & $1.052(0.990-1.119)$ & 0.1042 & $0.990(0.860-1.141)$ & 0.8936 \\
\hline mRS of $0-2$ & $283 / 689(41.1 \%)$ & $375 / 987(38.0 \%)$ & $1.052(0.972-1.139)$ & 0.2073 & $0.998(0.855-1.164)$ & 0.9782 \\
\hline \multicolumn{7}{|l|}{ Functional outcomes at 90 days } \\
\hline mRS of $0-1$ & $227 / 643(35.3 \%)$ & $315 / 959(32.9 \%)$ & $1.038(0.966-1.116)$ & 0.3120 & $0.962(0.839-1.104)$ & 0.5815 \\
\hline mRS of $0-2$ & $343 / 643(53.3 \%)$ & $530 / 959(55.3 \%)$ & $1.036(0.945-1.136)$ & 0.4508 & $0.957(0.805-1.138)$ & 0.6207 \\
\hline
\end{tabular}

CI, confidence interval; NINDS, National Institute of Neurological Disorders and Stroke; RR relative risk; SITS-MOST, Safe Implementation of Thrombolysis in Stroke-Monitoring Study; TG, Triglycerides. * Statistically significant at $p<0.05$. 'Poisson regression was adjusted for age, weight, atrial fibrillation, baseline NIHSS, and dose of alteplase.

\section{Results}

\section{Baseline Demographic Characteristics}

A total of 2373 patients with acute ischemic stroke who completed the IV thrombolysis treatment between December 1, 2004 and December 31, 2016 were registered in TTT-AIS I and II systems (Fig.1). Complete lipid profile data in a fasting state were measured in 1845 patients following admission (Table 1). The hyperlipidemia cohort included 747 patients, and the non-hyperlipidemia cohort included 1093 patients. The non-hyperlipidemia group was more likely to include older patients, those with a comorbidity of atrial fibrillation, those using aspirin, those with higher baseline NIHSS scores, and those using low-dose alteplase. The hyperlipidemia group consisted of more patients with higher systolic and diastolic blood pressure at arrival. There were no significant differences in the sex distribution; comorbidities of hypertension, diabetes mellitus, coronary artery disease, and alcoholism; or time from stroke onset to IV thrombolysis between the two groups.

\section{Primary Objective (Hyperlipidemia vs Non-Hyper- lipidemia Group)}

The rates of any intracranial hemorrhage (ICH) were $12.3 \%$ and $15.6 \%$ for hyperlipidemia and nonhyperlipidemia groups, respectively (Fig.1). Rates of SICH for hyperlipidemia and non-hyperlipidemia groups according to the NINDS, ECASS II, and SITSMOST standards are shown in Table 2. The hyperlipidemia group had a significantly reduced incidence rate of SICH than the non-hyperlipidemia group by the NINDS standard $(2.28 \%$ vs $4.85 \%$; adjusted RR, $0.509 ; 95 \% \mathrm{CI}, 0.277-0.933 ; p=0.0290)$, the ECASS
II standard (1.07\% vs $2.74 \%$; adjusted RR, 0.318; $95 \%$ CI, $0.130-0.777 ; p=0.0119)$, and the SITS-MOST standard $(0.27 \%$ vs $1.46 \%$; adjusted RR, $0.216 ; 95 \%$ CI, $0.048-0.966 ; p=0.0119)$. The continuing survey showed that the hyperlipidemia group had more patients who attained favorable functional outcomes ( $\mathrm{mRS}$ of $0-1)$ than the non-hyperlipidemia group at 30 days $(29.9 \%$ vs $26.2 \%$; adjusted $\mathrm{RR}, 0.990$; $95 \% \mathrm{CI}$, $0.860-1.141 ; p=0.8963)$ and 90 days $(35.3 \%$ vs $32.9 \%$; adjusted RR, 0.962; 95\% CI, 0.839-1.104; $p=0.5815)$. There was no significance difference for obtaining the favorable functional outcomes between the two groups (Fig.2).

\section{Secondary Objective (Each Lipid Profile)}

The association between SICH and each lipid profile is shown in Table 3. Increasing total cholesterol and TG levels decreased the risk of developing SICH, but they showed solitary significance in the ECASS II standard (adjusted RR, 0.908 per $10 \mathrm{mg} /$ dL; 95\% CI, 0.830-0.992; $p=0.0331)$ and the SITSMOST (adjusted RR, 0.837 per $10 \mathrm{mg} / \mathrm{dL} ; 95 \% \mathrm{CI}$, $0.722-0.970 ; p=0.0331$ ), respectively. By contrast, only LDL-C showed a significant association with all SICH standards - the NINDS standard (adjusted RR, 0.912 per $10 \mathrm{mg} / \mathrm{dL} ; 95 \%$ CI, $0.848-0.982 ; p=0.0145$ ), the ECASS II standard (adjusted RR, 0.823 per 10 $\mathrm{mg} / \mathrm{dL} ; 95 \% \mathrm{CI}, 0.742-0.913 ; p=0.0002)$, and the SITS-MOST standard (adjusted RR, 0.846 per $10 \mathrm{mg} /$ dL; 95\% CI, 0.724-0.989; $p=0.0358$ ). The increased HDL-C level manifested an increased risk of SICH, but it was exclusively significant for the ECASS II standard (adjusted RR, 0.837 per $10 \mathrm{mg} / \mathrm{dL} ; 95 \% \mathrm{CI}$, $0.722-0.970 ; p=0.0182)$. 


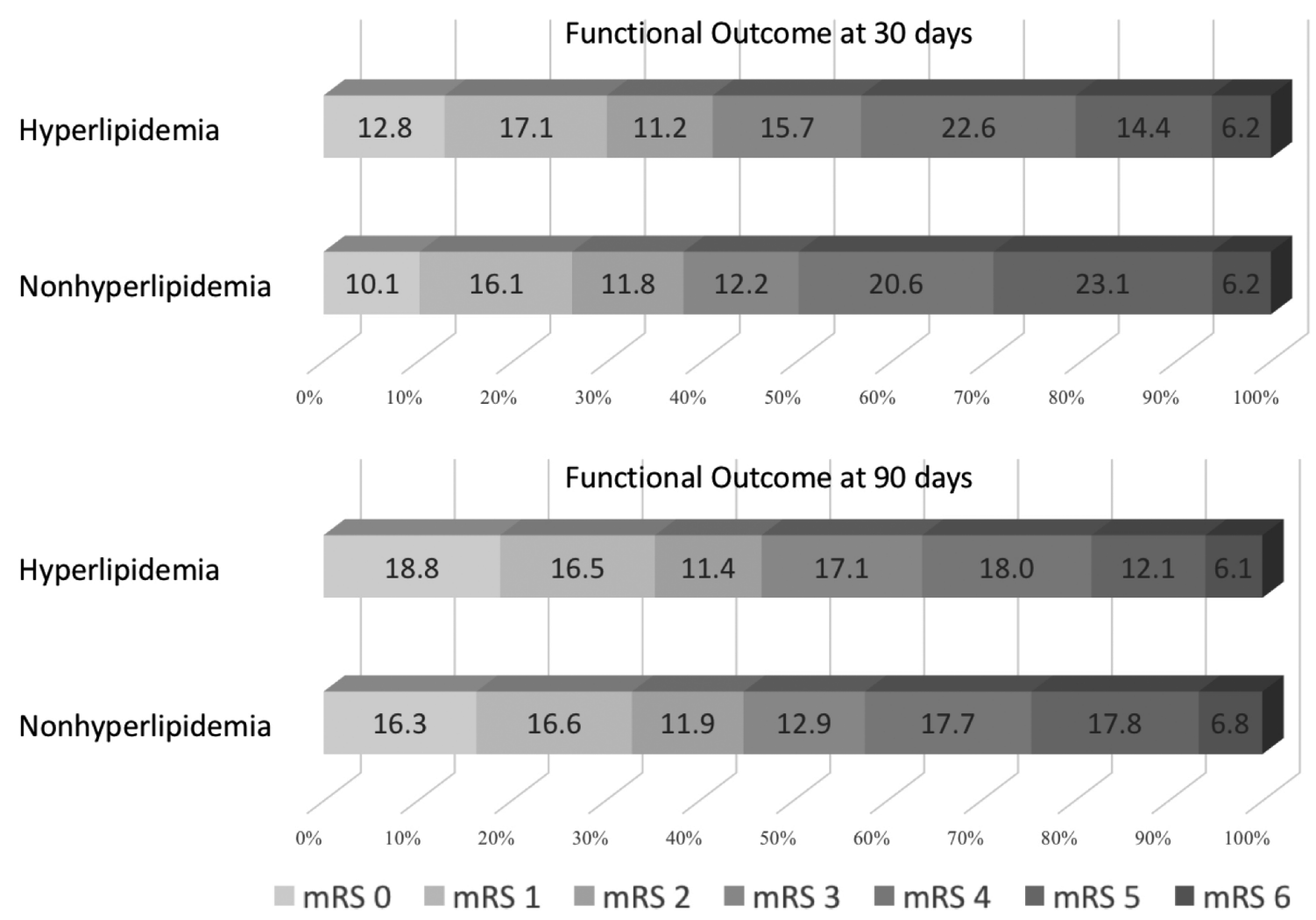

Fig. 2. The distribution of functional outcomes at 30 and 90 days.

\section{Validation Study}

LDL-C, which exhibited the most robust association with $\mathrm{SICH}$ in our study, was incorporated into all of our available and validated hemorrhagic transformation predicting models in two ways: continuous level and discrete points. To obtain a higher sensitivity, we determined a cut-off of LDL-C of $100-130 \mathrm{mg} /$ $\mathrm{dL}$ as a point of 1 , and LDL-C $<100 \mathrm{mg} / \mathrm{dL}$ as a point of 2 . For the new models with LDL-C as continuous levels, all the models showed significantly exceeding improvement in diagnostic ability. The ROC contrast results were all significant as well (Supplemental Table 2). In addition, the diagnostic ability of all models improved on adding the LDL-C discrete points, and most of them were effective in model stability and fitness (Supplemental Table 3). By applying the new models, our patients had better predictability of SICH in the NINDS standard (Fig.3), the ECASS II standard (Supplemental Fig.1), and STIS-MOST standard (Supplemental Fig. 2).

\section{Discussion}

In this investigation, hyperlipidemia had a robust protective effect on the development of SICH among patients with acute ischemic stroke treated with IV thrombolysis, but not for the favorable functional outcomes at 30 and 90 days. The study confirmed that the association between the lipid profile and SICH was mostly attributable to LDL-C, and a level of LDL-C $<130 \mathrm{mg} / \mathrm{dL}$ had the greatest significant association with increased SICH.

In our cohorts, the ICH and SICH rates varied according to the NINDS, ECASS II, and SITS-MOST. Because the SITS-MOST standard had the most conservative definition, the SICH rates were markedly reduced in the hyperlipidemia and non-hyperlipidemia groups $(0.27 \%$ and $1.46 \%$, respectively). This was comparable to previous literature ${ }^{13,14)}$ and also reflected realworld data among Asian population. Moreover, our cohorts had high follow-up rates in both groups $(92.2 \%$ and $90.4 \%$, respectively, at 30 days; $86.1 \%$ and $87.7 \%$, respectively, at 90 days). These high follow-up rates should strengthen our research by avoiding the selection bias.

In the validation section, we confirmed LDL-C had high diagnostic ability in predicting hemorrhagic transformation. Each of the modified risk scoring model implementing LDL-C variable had higher ROC statistics (the area under curve) in predicting $\mathrm{SICH}$ and maintained stable goodness of fit. The modified models in a way of LDL-C discrete points also exempted 
Table 3. Analysis of the Risk of Symptomatic Intracranial Hemorrhage (SICH) for Each Lipid Profile.

\begin{tabular}{|c|c|c|c|c|}
\hline Variable & $\begin{array}{c}\text { RR } \\
(95 \% \mathrm{CI})\end{array}$ & $p$ value & $\begin{array}{c}\text { Adjusted RR } \\
(95 \% \mathrm{CI})^{\dagger}\end{array}$ & $p$ value \\
\hline \multicolumn{5}{|c|}{ Total cholesterol (per $10 \mathrm{mg} / \mathrm{dl}$ increase) } \\
\hline SICH by ECASS II & $0.937(0.867-1.013)$ & 0.0999 & $0.908(0.830-0.992)$ & $0.0331^{*}$ \\
\hline SICH by SITS-MOST & $0.895(0.798-1.004)$ & 0.0588 & $0.919(0.766-1.102)$ & 0.3623 \\
\hline SICH by ECASS II & $0.874(0.801-0.954)$ & $0.0026^{*}$ & $0.823(0.742-0.913)$ & $0.0002 *$ \\
\hline SICH by SITS-MOST & $0.881(0.776-0.999)$ & $0.0493^{*}$ & $0.846(0.724-0.989)$ & $0.0358^{*}$ \\
\hline \multicolumn{5}{|c|}{ HDL-C (per 10 mg/dl increase) } \\
\hline SICH by NINDS & $1.077(1.013-1.144)$ & $0.0171^{*}$ & $1.064(0.992-1.140)$ & 0.0826 \\
\hline SICH by ECASS II & $1.087(1.005-1.175)$ & $0.0171^{*}$ & $1.085(1.005-1.171)$ & 0.0379 \\
\hline SICH by SITS-MOST & $0.904(0.809-1.091)$ & 0.0719 & $0.837(0.722-0.970)$ & $0.0182^{*}$ \\
\hline
\end{tabular}

HDL-C, high-density lipoprotein cholesterol; LDL-C, low-density lipoprotein cholesterol; NINDS, National Institute of Neurological Disorders and Stroke; RR, relative risk, CI, confidence interval; SITS-MOST, Safe Implementation of Thrombolysis in Stroke-Monitoring Study; TG, triglycerides. * Statistically significant at $p<0.05$. Poisson regression adjusted for age, weight, atrial fibrillation, baseline NIHSS, and dose of alteplase.

from the doubt of increasing diagnostic ability by adding another variable. For an example, the discrete points models of HAT score synthesized all scoring variables (including the LDL-C) into single value in a range from $0,1,2, \geq 3$ which called as total score. Only the total score was used as the independent variable in these modified models. These modified models verified our judgment and raised the practical ability (Fig.3, Supplemental Figs. 1 and 2).

From earlier studies such as the INTERSTROKE study, we recognized that non-HDL-C was possibly connected with spontaneous ICH occurrence. Our study showed that increased TG may be protective, but it was only significant in the SITS-MOST standard. Referred to the previous literature of TG, which showed inconsistent results ${ }^{28-32)}$, we supposed TG was not a reliable marker for hemorrhagic transformation. For increased HDL-C level, our results showed a paradoxically raised risk of hemorrhagic transformation despite only significant in the ECASS II standard. The relevant studies showed a similar trend for HDL-C $\left.{ }^{29}, 30,33,34\right)$, but most of their results were not significant like our study results. Regarding LDL-C, a recent study proposed that admission ICH volume in cube root was inversely proportional to admission LDL-C levels ${ }^{35)}$. We considered that low LDL-C may modify the SICH through increasing ICH volume expansion, but all lipid profiles did not effectively alter the long-term outcomes. This warrants further studies.
The distinctive strengths of our study are (1) a longitudinal cohort study design with a large sample size of patients treated with a thrombolytic agent in comparison to previous studies, (2) determination of how much a lower level of LDL-C contributed to increase hemorrhagic transformation of SICH, (3) a solid definition of SICH by the NINDS, ECASS II, and SITS-MOST standards, (4) a validation study to substantiate our findings, and (5) a proper statistical estimation. We adopted the Poisson regression instead of logistic regression model because the former produces a more unbiased estimate when adjusting for confounders $^{36,37)}$ and our prime data fulfilled the assumption of the Poisson regression (the count of SICH events was rare and the sample size of enrolled patients was large).

This study has some limitations. First, the TTTAIS registry ${ }^{13,14)}$ has no exact information on whether patients treated with a thrombolytic agent took statins. However, we may identify the patients who were possibly statin-naive because the TNHI system had strict payment rule for statin and covered all residents in Taiwan. Although we cannot thoroughly discuss the interaction with statins, we found that these possibly statin-naive patients still had an increased association between low LDL-C and SICH (Supplemental Fig. 3 and Supplemental Table 4). Second, the TTT-AIS registry $\left.{ }^{13}, 14\right)$ had not enrolled patients treated with intra-arterial thrombectomy. The TTT-AIS was launched in 2004 at that time the intra-arterial thrombectomy 
Validation Study with adding LDL-C for Current Risk-Scoring Systems for predicting hemorrhagic transformation

HAT Score

- HAT $\square$ HAT (new)
SITS-SICH Score

- $\mathrm{SITS}-\mathrm{SICH} \quad$ घSITS-SICH (new)
Cucchiara Score

- Cucchiara $n$ Cucchiara (new)

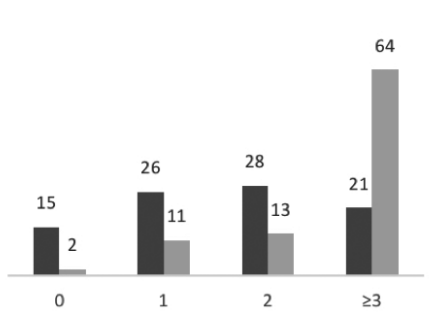

SEDAN Score

- SEDAN $=$ SEDAN (new)

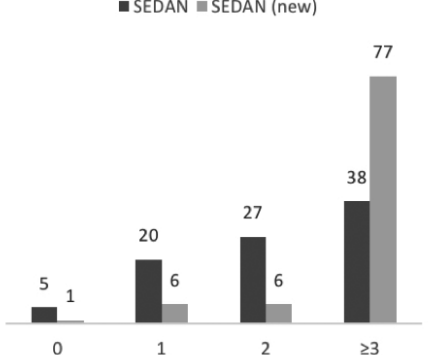

Thrive Score

-THRIVE $=$ THRIVE (new)
GRASP Score

- GRASP $=$ GRASP (new)

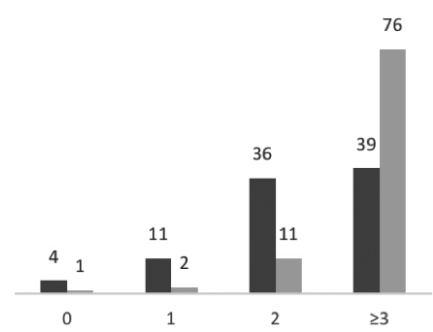

76

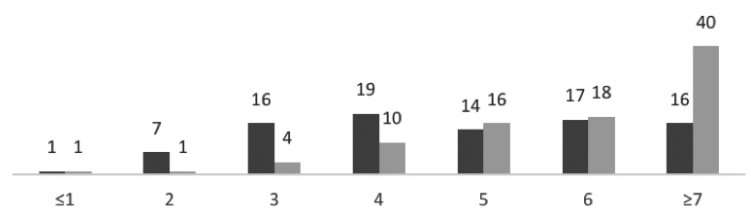

SPAN-100 index

- SPAN-100 $\because$ SPAN-100 (new)

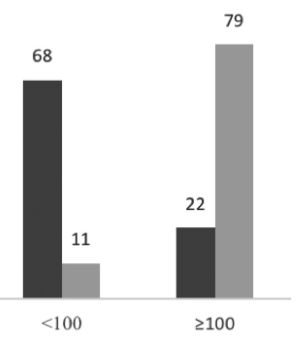

- Horizontal Axis: the score of each risk-scoring system

- Vertical Axis: the number of patients who developed hemorrhagic transformation by the NINDS standard

Fig. 3. Validation study with adding discrete LDL-C scores as the new model. All of the new models (gray bar) were more accurate in predicting SICH by the NINDS standard.

technique had not been introduced in Taiwan. Third, the TTT-AIS registry had no nutrient-related information. Nonetheless, our results should stay free from the doubt of malnutrition influence. Compared to the neighboring Asian countries, the National Health and Nutrition Examination Survey (NHANES) ${ }^{38)}$ in Taiwan reported that our population had the highest average number of body mass index and metabolic syndrome, and the prevalence of obesity was also proportional to increasing age. These also highlight the importance of this research investigating the association between thrombolytic outcomes and lipid profiles.

In conclusion, this study supports an association between reduced lipid profiles and increased SICH among patients with acute ischemic stroke treated with IV thrombolysis. LDL-C level of $<130 \mathrm{mg} / \mathrm{dL}$ is a candidate marker indicating increased $\mathrm{SICH}$ after IV thrombolysis.

\section{Acknowledgments}

Each author contributed to the conception and design of the study, acquisition, analysis, and interpre- tation of data. S.F.L wrote the first draft of the article.

\section{Funding}

This study was supported by grants from Ministry of Science and Technology (MOST) 104-2314-B037-029- and KMUH 104-4R53.

\section{Conflicts of Interests}

The authors have no conflicts of interests to declare.

\section{References}

1) O'Donnell MJ, Xavier D, Liu L, Zhang H, Chin SL, Rao-Melacini P, Rangarajan S, Islam S, Pais P, McQueen MJ, Mondo C, Damasceno A, Lopez-Jaramillo P, Hankey GJ, Dans AL, Yusoff K, Truelsen T, Diener HC, Sacco RL, Ryglewicz D, Czlonkowska A, Weimar C, Wang X, Yusuf $S$ and investigators I: Risk factors for ischaemic and intracerebral haemorrhagic stroke in 22 countries (the INTERSTROKE study): a case-control study. Lancet, 2010; 376: 112-123 
2) Wang X, Dong Y, Qi X, Huang C and Hou L: Cholesterol levels and risk of hemorrhagic stroke: a systematic review and meta-analysis. Stroke, 2013; 44: 1833-1839

3) Kim BJ, Lee SH, Ryu WS, Kang BS, Kim CK and Yoon BW: Low level of low-density lipoprotein cholesterol increases hemorrhagic transformation in large artery atherothrombosis but not in cardioembolism. Stroke, 2009; 40: 1627-1632

4) Noda H, Iso H, Irie F, Sairenchi T, Ohtaka E, Doi M, Izumi $Y$ and Ohta H: Low-density lipoprotein cholesterol concentrations and death due to intraparenchymal hemorrhage: the Ibaraki Prefectural Health Study. Circulation, 2009; 119: 2136-2145

5) Bang OY, Saver JL, Liebeskind DS, Starkman S, Villablanca P, Salamon N, Buck B, Ali L, Restrepo L, Vinuela F, Duckwiler G, Jahan R, Razinia T and Ovbiagele B: Cholesterol level and symptomatic hemorrhagic transformation after ischemic stroke thrombolysis. Neurology, 2007; 68: 737742

6) Meier N, Nedeltchev K, Brekenfeld C, Galimanis A, Fischer U, Findling O, Remonda L, Schroth G, Mattle HP and Arnold M: Prior statin use, intracranial hemorrhage, and outcome after intra-arterial thrombolysis for acute ischemic stroke. Stroke, 2009; 40: 1729-1737

7) Montaner J: Cholesterol measured before stroke thrombolysis is not associated with tissue plasminogen activatorrelated hemorrhagic transformation. Stroke, 2008; 39: e6

8) Rocco A, Sykora M, Ringleb P and Diedler J: Impact of statin use and lipid profile on symptomatic intracerebral haemorrhage, outcome and mortality after intravenous thrombolysis in acute stroke. Cerebrovasc Dis, 2012; 33: 362-368

9) Messé SR, Pervez MA, Smith EE, Siddique KA, Hellkamp AS, Saver JL, Bhatt DL, Fonarow GC, Peterson ED and Schwamm LH: Lipid profile, lipid-lowering medications, and intracerebral hemorrhage after tPA in get with the guidelines-stroke. Stroke, 2013; 44: 1354-1359

10) Uyttenboogaart M, Koch MW, Koopman K, Vroomen PC, Luijckx GJ and De Keyser J: Lipid profile, statin use, and outcome after intravenous thrombolysis for acute ischaemic stroke. J Neurol, 2008; 255: 875-880

11) Mascitelli L and Pezzetta F: Low LDL cholesterol, statins, and brain hemorrhage: should we worry? Neurology, 2007; 69: 1061; author reply 1061-1062

12) Goldstein LB: Low LDL cholesterol, statins, and brain hemorrhage: should we worry? Neurology, 2007; 68: 719720

13) Chao AC, Hsu HY, Chung CP, Liu CH, Chen $\mathrm{CH}$, Teng MM, Peng GS, Sheng WY, Hu HH and Group TTTfAIST-AS: Outcomes of thrombolytic therapy for acute ischemic stroke in Chinese patients: the Taiwan Thrombolytic Therapy for Acute Ischemic Stroke (TTT-AIS) study. Stroke, 2010; 41: 885-890

14) Chao AC, Liu CK, Chen $\mathrm{CH}$, Lin HJ, Liu CH, Jeng JS, $\mathrm{Hu}$ CJ, Chung CP, Hsu HY, Sheng WY, Hu HH and Group TTTfAIST-AS: Different doses of recombinant tissue-type plasminogen activator for acute stroke in Chinese patients. Stroke, 2014; 45: 2359-2365

15) Group NIoNDaSr-PSS: Tissue plasminogen activator for acute ischemic stroke. N Engl J Med, 1995; 333: 1581 1587
16) Wahlgren N, Ahmed N, Dávalos A, Ford GA, Grond M, Hacke W, Hennerici MG, Kaste M, Kuelkens S, Larrue V, Lees KR, Roine RO, Soinne L, Toni D, Vanhooren G and investigators S-M: Thrombolysis with alteplase for acute ischaemic stroke in the Safe Implementation of Thrombolysis in Stroke-Monitoring Study (SITS-MOST): an observational study. Lancet, 2007; 369: 275-282

17) Weisscher N, Vermeulen M, Roos $Y B$ and de Haan RJ: What should be defined as good outcome in stroke trials; a modified Rankin score of $0-1$ or $0-2$ ? J Neurol, 2008; 255: 867-874

18) Hacke W, Kaste M, Fieschi C, von Kummer R, Davalos A, Meier D, Larrue V, Bluhmki E, Davis S, Donnan G, Schneider D, Diez-Tejedor E and Trouillas P: Randomised double-blind placebo-controlled trial of thrombolytic therapy with intravenous alteplase in acute ischaemic stroke (ECASS II). Second European-Australasian Acute Stroke Study Investigators. Lancet, 1998; 352: 1245-1251

19) Lou M, Safdar A, Mehdiratta M, Kumar S, Schlaug G, Caplan L, Searls D and Selim M: The HAT Score: a simple grading scale for predicting hemorrhage after thrombolysis. Neurology, 2008; 71: 1417-1423

20) Mazya M, Egido JA, Ford GA, Lees KR, Mikulik R, Toni $\mathrm{D}$, Wahlgren N, Ahmed N and Investigators S: Predicting the risk of symptomatic intracerebral hemorrhage in ischemic stroke treated with intravenous alteplase: safe Implementation of Treatments in Stroke (SITS) symptomatic intracerebral hemorrhage risk score. Stroke, 2012; 43: 15241531

21) Cucchiara B, Tanne D, Levine SR, Demchuk AM and Kasner S: A risk score to predict intracranial hemorrhage after recombinant tissue plasminogen activator for acute ischemic stroke. J Stroke Cerebrovasc Dis, 2008; 17: 331333

22) Strbian D, Engelter S, Michel P, Meretoja A, Sekoranja L, Ahlhelm FJ, Mustanoja S, Kuzmanovic I, Sairanen T, Forss N, Cordier M, Lyrer P, Kaste M and Tatlisumak T: Symptomatic intracranial hemorrhage after stroke thrombolysis: the SEDAN score. Ann Neurol, 2012; 71: 634-641

23) Saposnik G, Guzik AK, Reeves M, Ovbiagele B and Johnston SC: Stroke Prognostication using Age and NIH Stroke Scale: SPAN-100. Neurology, 2013; 80: 21-28

24) Menon BK, Saver JL, Prabhakaran S, Reeves M, Liang L, Olson DM, Peterson ED, Hernandez AF, Fonarow GC, Schwamm LH and Smith EE: Risk score for intracranial hemorrhage in patients with acute ischemic stroke treated with intravenous tissue-type plasminogen activator. Stroke, 2012; 43: 2293-2299

25) Flint AC, Faigeles BS, Cullen SP, Kamel H, Rao VA, Gupta R, Smith WS, Bath PM, Donnan GA and Collaboration $\mathrm{V}$ : THRIVE score predicts ischemic stroke outcomes and thrombolytic hemorrhage risk in VISTA. Stroke, 2013; 44: 3365-3369

26) Kerr KF, McClelland RL, Brown ER and Lumley T: Evaluating the incremental value of new biomarkers with integrated discrimination improvement. Am J Epidemiol, 2011; 174: 364-374

27) Cook NR and Paynter NP: Performance of reclassification statistics in comparing risk prediction models. Biom J, 2011; 53: 237-258

28) Bonaventure A, Kurth T, Pico F, Barberger-Gateau P, 
Ritchie K, Stapf C and Tzourio C: Triglycerides and risk of hemorrhagic stroke vs. ischemic vascular events: The Three-City Study. Atherosclerosis, 2010; 210: 243-248

29) Wieberdink RG, Poels MM, Vernooij MW, Koudstaal PJ, Hofman A, van der Lugt A, Breteler MM and Ikram MA: Serum lipid levels and the risk of intracerebral hemorrhage: the Rotterdam Study. Arterioscler Thromb Vasc Biol, 2011; 31: 2982-2989

30) Sturgeon JD, Folsom AR, Longstreth WT, Shahar E, Rosamond WD and Cushman M: Risk factors for intracerebral hemorrhage in a pooled prospective study. Stroke, 2007; 38: 2718-2725

31) Zia E, Pessah-Rasmussen H, Khan FA, Norrving B, Janzon L, Berglund G and Engstrom G: Risk factors for primary intracerebral hemorrhage: a population-based nested case-control study. Cerebrovasc Dis, 2006; 21: 18-25

32) Zhou JF, Wang JY, Luo YE and Chen HH: Influence of hypertension, lipometabolism disorders, obesity and other lifestyles on spontaneous intracerebral hemorrhage. Biomed Environ Sci, 2003; 16: 295-303

33) Bots ML, Elwood PC, Nikitin Y, Salonen JT, Freire de Concalves A, Inzitari D, Sivenius J, Benetou V, Tuomilehto J, Koudstaal PJ and Grobbee DE: Total and HDL choles- terol and risk of stroke. EUROSTROKE: a collaborative study among research centres in Europe. J Epidemiol Community Health, 2002; 56 Suppl 1: i19-24

34) Tirschwell DL, Smith NL, Heckbert SR, Lemaitre RN, Longstreth WT and Psaty BM: Association of cholesterol with stroke risk varies in stroke subtypes and patient subgroups. Neurology, 2004; 63: 1868-1875

35) Chang JJ, Katsanos AH, Khorchid Y, Dillard K, Kerro A, Burgess LG, Goyal N, Alexandrov AW, Alexandrov AV and Tsivgoulis G: Higher low-density lipoprotein cholesterol levels are associated with decreased mortality in patients with intracerebral hemorrhage. Atherosclerosis, 2018; 269: 14-20

36) Karp I: Re: "Estimating the relative risk in cohort studies and clinical trials of common outcomes". Am J Epidemiol, 2014; 179: 1034-1035

37) McNutt LA, Wu C, Xue X and Hafner JP: Estimating the relative risk in cohort studies and clinical trials of common outcomes. Am J Epidemiol, 2003; 157: 940-943

38) Yeh CJ, Chang HY and Pan WH: Time trend of obesity, the metabolic syndrome and related dietary pattern in Taiwan: from NAHSIT 1993-1996 to NAHSIT 20052008. Asia Pac J Clin Nutr, 2011; 20: 292-300 
Supplemental Table 1. The Risk-scoring Models Used in Validation Study.

\begin{tabular}{|c|c|c|c|}
\hline Model & Variables Needed & $\begin{array}{l}\text { Cut-off values } \\
\text { (points obtained for each item) }\end{array}$ & $\begin{array}{l}\text { Original Definition } \\
\text { of SICH }\end{array}$ \\
\hline HAT score $^{1}$ & $\begin{array}{l}\text { NIHSS, } \\
\text { Glucose }>200 \mathrm{mg} / \mathrm{dl} \text { or } \\
\text { Diabetes mellitus, } \\
\text { Hypodensity on CT }\end{array}$ & $\begin{array}{l}15-20(1), \\
>20(2), \\
\text { yes }(1), \\
<1 / 3 \text { of MCA territory }(1), \\
\geq 1 / 3 \text { of MCA territory }(2),\end{array}$ & NINDS \\
\hline SITS-SICH score $^{2}$ & $\begin{array}{l}\text { Age, } \\
\text { NIHSS, } \\
\text { Glucose, } \\
\text { Systolic blood pressure, } \\
\text { Weight, } \\
\text { Onset to thrombolytic time, } \\
\text { Aspirin monotherapy, } \\
\text { Aspirin + clopidogrel, } \\
\text { Hypertension, }\end{array}$ & $\begin{array}{l}\geq 72(1), \\
7-12(1), \\
\geq 13(2), \\
\geq 180 \mathrm{mg} / \mathrm{dl}(2), \\
\geq 146 \mathrm{mmHg}(1), \\
\geq 95 \mathrm{~kg}(1), \\
\geq 180 \mathrm{~min}(1), \\
\text { yes }(2), \\
\text { yes (3), } \\
\text { yes (1), }\end{array}$ & SITS-MOST \\
\hline Cucchiara Score $^{3}$ & $\begin{array}{l}\text { Age, } \\
\text { NIHSS, } \\
\text { Glucose, } \\
\text { Platelet count, }\end{array}$ & $\begin{array}{l}>60(1) \\
>10(1) \\
>150 \mathrm{mg} / \mathrm{dl}(1) \\
<150,000 / \mathrm{mm}^{3}(1)\end{array}$ & NINDS \\
\hline SEDAN Score ${ }^{4}$ & $\begin{array}{l}\text { Glucose, } \\
\text { Early infarct on CT } \\
\text { Dense cerebral artery sign on CT, } \\
\text { Age, } \\
\text { NIHSS, }\end{array}$ & $\begin{array}{l}145-216 \mathrm{mg} / \mathrm{dl}(1) \\
>216 \mathrm{mg} / \mathrm{dl}(2) \\
\text { yes }(1) \\
\text { yes }(1) \\
>75(1) \\
\geq 10(1)\end{array}$ & ECASS II \\
\hline SPAN-100 index ${ }^{5}$ & Age + NIHSS & $\geq 100(1)$ & NINDS \\
\hline GRASP score $^{6}$ & $\begin{array}{l}\text { Age, } \\
\text { NIHSS, } \\
\text { Glucose, } \\
\text { Systolic blood pressure, } \\
\text { Ethnicity, } \\
\text { Gender }\end{array}$ & $\begin{array}{l}\leq 60(8), \\
61-70(11), \\
71-80(15), \\
>80(17), \\
0-5(20), \\
6-10(27), \\
11-15(34), \\
16-20(40), \\
>20(42), \\
<100(2) \\
100-149(6), \\
\geq 150(8) \\
<120(10), \\
120-149(14), \\
150-179(18), \\
\geq 180(21), \\
\text { Asian (9), } \\
\text { Non-Asian (0), } \\
\text { Male (4), } \\
\text { Female (0), }\end{array}$ & NINDS \\
\hline THRIVE score ${ }^{7}$ & $\begin{array}{l}\text { Age, } \\
\text { NIHSS, } \\
\text { Hypertension, } \\
\text { Diabetes mellitus, } \\
\text { Atrial fibrillation, }\end{array}$ & $\begin{array}{l}60-79(1), \\
\geq 80(2), \\
11-20(2), \\
\geq 21(4), \\
\text { yes }(1), \\
\text { yes (1), } \\
\text { yes (1), }\end{array}$ & \\
\hline
\end{tabular}

ECASS II, the European Cooperative Acute Stroke Study II; GRASPS, the Glucose Race Age Sex Pressure Stroke Severity study; HAT, the Hemorrhage After Thrombolysis study; MCA, middle cerebral artery; NINDS, the National Institute of Neurological Disorders and Stroke study; SEDAN, the blood Sugar, Early infarct signs and hyperDense cerebral artery sign, Age, and NIHSS; SICH, symptomatic intracerebral hemorrhage; SPAN-100, the Stroke Prognostication using Age and National Institutes of Health Stroke Scaleand-100 index. 
Supplemental Table 2. The Original and New Models with LDL variable (continuous) for Predicting Symptomatic Intracranial Hemorrhage.

\begin{tabular}{|c|c|c|c|c|c|c|c|c|c|}
\hline & $\begin{array}{l}\text { Model Odds Ratio } \\
\text { (per score change) }\end{array}$ & $P$ value & $\begin{array}{l}\text { LDL Odds Ratio } \\
\text { (per mg/dL change) }\end{array}$ & $P$ value & $\begin{array}{c}\mathrm{ROC} c \\
\text { statistics }\end{array}$ & $\begin{array}{l}\text { IDI } \\
(\%)\end{array}$ & $P$ value & $\begin{array}{l}\text { Hosmer-Lemeshow } \\
\text { statistics }\left(\chi^{2}\right)\end{array}$ & $P$ value \\
\hline \multicolumn{10}{|c|}{ Original Models by the NINDS Standard } \\
\hline HAT & $1.739(1.427-2.120)$ & $<0.0001^{*}$ & - & - & 0.6575 & - & - & 0.153 (4 groups) & 0.9265 \\
\hline SITS-SICH & $1.312(1.179-1.461)$ & $<0.0001^{*}$ & - & - & 0.6310 & - & - & 4.259 (7 groups) & 0.5128 \\
\hline Cucchiara & $1.750(1.375-2.227)$ & $<0.0001^{*}$ & - & - & 0.6358 & - & - & 2.596 (4 groups) & 0.2731 \\
\hline SEDAN & $1.599(1.334-1.917)$ & $<0.0001 *$ & - & - & 0.6521 & - & - & 3.338 (5 groups) & 0.3424 \\
\hline SPAN-100 & $2.147(1.308-3.525)$ & $0.0025^{*}$ & - & - & 0.5567 & - & - & - & - \\
\hline GRASPS & $1.074(1.047-1.102)$ & $<0.0001^{*}$ & - & - & 0.6698 & - & - & 6.995 (9 groups) & 0.4294 \\
\hline THRIVE & $1.299(1.162-1.453)$ & $<0.0001^{*}$ & - & - & 0.6392 & - & - & 2.338 (7 groups) & 0.8007 \\
\hline
\end{tabular}

New model with LDL-C by the NINDS Standard

$\begin{array}{llr}\text { HAT } & 1.740(1.404-2.157) & <0.0001^{*} \\ \text { SITS-SICH } & 1.319(1.172-1.484) & <0.0001^{*} \\ \text { Cucchiara } & 1.956(1.504-2.545) & <0.0001^{*} \\ \text { SEDAN } & 1.664(1.364-2.031) & <0.0001^{*} \\ \text { SPAN-100 } & 2.498(1.472-4.241) & 0.0007^{*} \\ \text { GRASPS } & 1.074(1.043-1.105) & <0.0001^{*} \\ \text { THRIVE } & 1.323(1.170-1.496) & <0.0001^{*}\end{array}$

Original Models by the ECASS II Standard

$\begin{array}{lcc}\text { HAT } & 1.702(1.321-2.194) & <0.0001^{*} \\ \text { SITS-SICH } & 1.377(1.215-1.586) & <0.0001^{*} \\ \text { Cucchiara } & 1.807(1.322-2.469) & 0.0002^{*} \\ \text { SEDAN } & 1.791(1.420-2.258) & <0.0001^{*} \\ \text { SPAN-100 } & 1.905(0.990-3.665) & 0.0536 \\ \text { GRASPS } & 1.084(1.048-1.122) & <0.0001^{*}\end{array}$

THRIVE $\quad 1.279(1.107-1.476) \quad 0.0008^{*}$

New model with LDL-C by the ECASS II Standard

$\begin{array}{lrr}\text { HAT } & 1.735(1.311-2.297) & <0.0001^{*} \\ \text { SITS-SICH } & 1.414(1.219-1.641) & <0.0001^{*} \\ \text { Cucchiara } & 2.012(1.425-2.843) & <0.0001^{*} \\ \text { SEDAN } & 1.978(1.524-2.567) & <0.0001^{*} \\ \text { SPAN-100 } & 2.657(1.346-5.246) & 0.0049^{*} \\ \text { GRASPS } & 1.088(1.047-1.130) & <0.0001^{*} \\ \text { THRIVE } & 1.324(1.127-1.556) & 0.0006^{*} \\ & & \\ \text { iginal Models by the SITS-MOST Standard } & \\ \text { HAT } & 2.359(1.634-3.495) & <0.0001^{*} \\ \text { SITS-SICH } & 1.416(1.179-1.701) & 0.0002^{*} \\ \text { Cucchiara } & 2.169(1.378-3.414) & 0.0008^{*} \\ \text { SEDAN } & 1.936(1.398-2.680) & <0.0001^{*} \\ \text { SPAN-100 } & 2.394(0.998-5.742) & 0.0504 \\ \text { GRASPS } & 1.093(1.041-1.147) & 0.0003^{*} \\ \text { THRIVE } & 1.387(1.128-1.705) & 0.0019^{*}\end{array}$

New model with LDL-C by the SITS-MOST Standard

$\begin{array}{llr}\text { HAT } & 2.662(1.733-4.091) & <0.0001^{*} \\ \text { SITS-SICH } & 1.489(1.207-1.836) & 0.0002^{*} \\ \text { Cucchiara } & 3.156(1.831-5.441) & <0.0001^{*} \\ \text { SEDAN } & 2.444(1.655-3.610) & <0.0001^{*} \\ \text { SPAN-100 } & 3.987(1.554-10.245) & 0.0040^{*} \\ \text { GRASPS } & 1.107(1.042-1.175) & <0.0001^{*} \\ \text { THRIVE } & 1.497(1.170-1.916) & 0.0013^{*}\end{array}$

$0.988(0.980-0.996) \quad 0.0042^{*}$ $0.988(0.980-0.996) \quad 0.0042 * 0.7067$ $0.988(0.980-0.996) \quad 0.0042 * 0.6997$ $0.988(0.980-0.996) \quad 0.0042 * 0.7670$ $0.988(0.980-0.996) \quad 0.0042 * 0.6524$ $0.988(0.980-0.996) \quad 0.0038^{*} \quad 0.7231$ $\begin{array}{lll}0.988(0.980-0.996) & 0.0042^{*} & 0.6981\end{array}$
$0.707 \quad 0.0034^{*}$ $0.6910 .0100^{*}$ $0.9040 .0003^{*}$ $0.8170 .0018^{*}$ $0.7750 .0006^{*}$ $0.6260 .0087^{*}$ $0.7730 .0010^{*}$
2.723 (10 groups) 11.856 (10 groups) 3.308 (10 groups) 20.615 (10 groups) 13.589 (10 groups) 5.629 (10 groups) 12.108 (10 groups)
0.9505

0.1578 0.9136 $0.0082^{*}$ 0.0931 0.6887 0.1465

0.6532
0.6638
0.6434
0.6975
0.5466
0.6890
0.6361

0.9222 (4 groups) 5.6208 (7 groups) 9.6871 (4 groups) 5.6336 ( 5 groups)

7.0191 (9 groups) 3.9933 (7 groups)
0.6306

0.3449 0.0079 *

0.1309

0.4269 0.5504 $\begin{array}{lll}0.475 & 0.0577 & 9.989 \text { (10 groups })\end{array}$ $0.7320 .0217^{*}$ $0.6560 .0184^{*}$ $0.6510 .0054^{*}$ $0.6590 .0051^{*}$ $\begin{array}{ll}0.510 & 0.0684\end{array}$ 0.5290 .0330 *
12.162 (10 groups) 12.171 (10 groups) 14.015 (10 groups) 14.253 (10 groups) 7.303 (10 groups) 14.008 (10 groups)
0.2658

0.1441

0.1437 0.0814 0.0754 0.5043 0.0815

\subsection{6 \\ 0.7090 \\ 0.6894 \\ 0.7185 \\ 0.5679 \\ 0.7041 \\ 0.6792}

$\begin{array}{ll}- & - \\ - & - \\ - & - \\ - & - \\ - & - \\ - & - \\ - & -\end{array}$

0.3629 (4 groups) 4.7692 (7 groups) 24.080 (4 groups) 2.869 (5 groups)

6.046 (9 groups) 10.576 (7 groups)
0.8341

0.4447 0.0001 * 0.4122

0.5343 0.0605

$\begin{array}{lllllrl}0.987(0.975-0.999) & 0.0373^{*} & 0.8098 & 0.613 & 0.0541 & 3.894(10 \text { groups }) & 0.8665 \\ 0.987(0.975-0.999) & 0.0373^{*} & 0.7680 & 0.419 & 0.0384^{*} & 8.473(10 \text { groups }) & 0.3887 \\ 0.987(0.975-0.999) & 0.0373^{*} & 0.7851 & 0.982 & 0.0391^{*} & 9.803(10 \text { groups }) & 0.2792 \\ 0.987(0.975-0.999) & 0.0373^{*} & 0.8179 & 0.347 & 0.0207^{*} & 12.351(10 \text { groups }) & 0.1362 \\ 0.987(0.975-0.999) & 0.0373^{*} & 0.6713 & 0.553 & 0.0277^{*} & 11.385(10 \text { groups }) & 0.1808 \\ 0.987(0.974-0.999) & 0.0356^{*} & 0.7512 & 0.476 & 0.0329^{*} & 2.384(10 \text { groups }) & 0.9669 \\ 0.987(0.975-0.999) & 0.0373^{*} & 0.7389 & 0.542 & 0.0839 & 14.946(10 \text { groups }) & 0.0602\end{array}$

ECASS II, the European Cooperative Acute Stroke Study II; GRASPS, Glucose Race Age Sex Pressure Stroke Severity; HAT, Hemorrhage After Thrombolysis; LDL-C, lower density lipoprotein-cholesterol; NINDS, National Institute of Neurological Disorders and Stroke; ROC, receiver operating characteristic; SICH, symptomatic intracerebral hemorrhage; SPAN-100, Stroke Prognostication using Age and National Institutes of Health Stroke Scaleand-100. 
Supplemental Table 3. Original and New Risk Scoring Systems Models with (discrete) LDL-C Scores for Predicting Symptomatic Intracranial Hemorrhage

\begin{tabular}{|c|c|c|c|c|c|}
\hline & $\begin{array}{l}\text { Model Odds Ratio } \\
\text { (per score change) }\end{array}$ & $P$ value & $\begin{array}{c}\text { ROC } c \\
\text { statistics }\end{array}$ & $\begin{array}{l}\text { Hosmer-Lemeshow } \\
\text { statistics }\end{array}$ & $P$ value \\
\hline \multicolumn{6}{|l|}{ Original models } \\
\hline $\begin{array}{l}\text { HAT } \\
\text { SITS-SICH } \\
\text { Cucchiara } \\
\text { SEDAN } \\
\text { SPAN-100 } \\
\text { GRASPS } \\
\text { THRIVE }\end{array}$ & $\begin{array}{l}1.739(1.427-2.120) \\
1.312(1.179-1.461) \\
1.750(1.375-2.227) \\
1.599(1.334-1.917) \\
2.147(1.308-3.525) \\
1.074(1.047-1.102) \\
1.299(1.162-1.453)\end{array}$ & $\begin{array}{rl}<0.0001 & * \\
<0.0001^{*} \\
<0.0001^{*} \\
<0.0001^{*} \\
0.0025^{*} \\
<0.0001^{*} \\
<0.0001^{*}\end{array}$ & $\begin{array}{l}0.6575 \\
0.6310 \\
0.6358 \\
0.6521 \\
0.5567 \\
0.6698 \\
0.6392\end{array}$ & $\begin{array}{c}0.1527 \text { (4 groups) } \\
4.2587 \text { (7 groups) } \\
2.5957 \text { (4 groups) } \\
3.3382 \text { (5 groups) } \\
- \\
6.9952 \text { ( } 9 \text { groups) } \\
2.3377 \text { (7 groups) }\end{array}$ & $\begin{array}{l}0.9265 \\
0.5128 \\
0.2731 \\
0.3424 \\
- \\
0.4294 \\
0.8007\end{array}$ \\
\hline \multicolumn{6}{|c|}{ New models with LDL-C risk scores by NINDS criteria } \\
\hline $\begin{array}{l}\text { HAT } \\
\text { SITS-SICH } \\
\text { Cucchiara } \\
\text { SEDAN } \\
\text { SPAN-100 } \\
\text { GRASPS } \\
\text { THRIVE }\end{array}$ & $\begin{array}{l}1.589(1.352-1.869) \\
1.327(1.200-1.467) \\
1.530(1.283-1.826) \\
1.560(1.333-1.825) \\
1.543(1.202-1.983) \\
1.077(1.049-1.104) \\
1.297(1.172-1.435)\end{array}$ & $\begin{aligned} &<0.0001^{*} \\
&<0.0001^{*}<0.0001^{*} \\
&<0.0001^{*} \\
& 0.0007^{*} \\
&<0.0001^{*} \\
&<0.0001^{*}\end{aligned}$ & $\begin{array}{l}0.6687 \\
0.6567 \\
0.6434 \\
0.6756 \\
0.5980 \\
0.6756 \\
0.6499\end{array}$ & $\begin{array}{l}4.4057 \text { ( } 6 \text { groups) } \\
0.6450 \text { ( } 7 \text { groups) } \\
0.1585 \text { ( } 5 \text { groups }) \\
4.5016 \text { ( } 5 \text { groups }) \\
2.2371 \text { ( } 4 \text { groups }) \\
4.0071 \text { ( } 10 \text { groups }) \\
8.4462 \text { ( } 7 \text { groups) }\end{array}$ & $\begin{array}{l}0.3539 \\
0.9859 \\
0.9840 \\
0.2117 \\
0.3268 \\
0.8565 \\
0.1333\end{array}$ \\
\hline \multicolumn{6}{|c|}{ New models with LDL-C risk scores by ECASS II criteria } \\
\hline $\begin{array}{l}\text { HAT } \\
\text { SITS-SICH } \\
\text { Cucchiara } \\
\text { SEDAN } \\
\text { SPAN-100 } \\
\text { GRASPS } \\
\text { THRIVE }\end{array}$ & $\begin{array}{l}1.601(1.300-1.973) \\
1.406(1.239-1.595) \\
1.800(1.357-2.388) \\
1.735(1.415-2.126) \\
1.581(1.411-2.190) \\
1.087(1.051-1.124) \\
1.290(1.132-1.470)\end{array}$ & $\begin{aligned} &<0.0001^{*}{ }^{<} 0.0001^{*} \\
&<0.0001^{*} \\
&<0.0001^{*} \\
& 0.0059^{*} \\
&<0.0001^{*} \\
&<0.0001^{*}\end{aligned}$ & $\begin{array}{l}0.6790 \\
0.6888 \\
0.6599 \\
0.7169 \\
0.6015 \\
0.6963 \\
0.6571\end{array}$ & $\begin{array}{l}4.9357 \text { (6 groups) } \\
7.4850 \text { ( } 7 \text { groups }) \\
3.1769 \text { ( } 5 \text { groups }) \\
1.4369 \text { ( } 5 \text { groups }) \\
1.2868 \text { ( } 4 \text { groups) } \\
5.5266 \text { ( } 10 \text { groups }) \\
9.7999 \text { ( } 7 \text { groups) }\end{array}$ & $\begin{array}{l}0.2940 \\
0.1870 \\
0.2042 \\
0.6969 \\
0.5255 \\
0.7001 \\
0.0811\end{array}$ \\
\hline \multicolumn{6}{|c|}{ New models with LDL-C risk scores by SITS-MOST criteria } \\
\hline
\end{tabular}

ECASS II, the European Cooperative Acute Stroke Study II; GRASPS, Glucose Race Age Sex Pressure Stroke Severity; HAT, Hemorrhage After Thrombolysis; LDL-C, Low density lipoprotein-cholesterol; NINDS, National Institute of Neurological Disorders and Stroke; ROC, receiver operating characteristic; SICH, symptomatic intracerebral hemorrhage; SPAN-100, Stroke Prognostication using Age and National Institutes of Health Stroke Scaleand-100.

Supplemental Table 4. Subcohort Analysis of Association between Lipid Profile and Symptomatic Intracranial Hemorrhage for Possibly Statin-naïve Patients

\begin{tabular}{|c|c|c|c|c|}
\hline $\begin{array}{l}\text { Variable } \\
(N=1245)\end{array}$ & $\begin{array}{c}\mathrm{RR} \\
(95 \% \mathrm{CI})\end{array}$ & $p$ value & $\begin{array}{c}\text { Adjusted RR } \\
(95 \% \mathrm{CI})\end{array}$ & $p$ value \\
\hline \multicolumn{5}{|c|}{ Total cholesterol (per $10 \mathrm{mg} / \mathrm{dl}$ increase) } \\
\hline $\begin{array}{l}\text { SICH by NINDS } \\
\text { SICH by ECASS II } \\
\text { SICH by SITS-MOST }\end{array}$ & $\begin{array}{l}0.948(0.869-1.035) \\
1.009(0.900-1.132) \\
0.985(0.837-1.159)\end{array}$ & $\begin{array}{l}0.2341 \\
0.8760 \\
0.8536\end{array}$ & $\begin{array}{l}0.971(0.879-1.072) \\
0.997(0.879-1.130) \\
0.934(0.764-1.140)\end{array}$ & $\begin{array}{l}0.5599 \\
0.9582 \\
0.4998\end{array}$ \\
\hline \multicolumn{5}{|c|}{ LDL-C (per 10 mg/dl increase) } \\
\hline $\begin{array}{l}\text { SICH by NINDS } \\
\text { SICH by ECASS II } \\
\text { SICH by SITS-MOST }\end{array}$ & $\begin{array}{l}0.866(0.789-0.950) \\
0.894(0.791-1.012) \\
0.991(0.821-1.198)\end{array}$ & $\begin{array}{l}0.0023^{*} \\
0.0760 \\
0.9289\end{array}$ & $\begin{array}{l}0.873(0.783-0.973) \\
0.856(0.746-0.983) \\
0.932(0.743-1.170)\end{array}$ & $\begin{array}{l}0.0143 \text { * } \\
0.0270 \\
0.5447\end{array}$ \\
\hline \multicolumn{5}{|c|}{ HDL-C (per 10 mg/dl increase) } \\
\hline \multicolumn{5}{|l|}{ TG (per $10 \mathrm{mg} / \mathrm{dl}$ increase) } \\
\hline $\begin{array}{l}\text { SICH by NINDS } \\
\text { SICH by ECASS II } \\
\text { SICH by SITS-MOST }\end{array}$ & $\begin{array}{l}0.982(0.938-1.027) \\
1.001(0.967-1.053) \\
0.944(0.850-1.048)\end{array}$ & $\begin{array}{l}0.4262 \\
0.6845 \\
0.2788\end{array}$ & $\begin{array}{l}1.000(0.959-1.044) \\
1.006(0.960-1.055) \\
0.882(0.761-1.022)\end{array}$ & $\begin{array}{l}0.9901 \\
0.7929 \\
0.0935\end{array}$ \\
\hline
\end{tabular}

HDL-C, high-density lipoprotein cholesterol; LDL-C, low-density lipoprotein cholesterol; N, total number of subcohort patients; NINDS, National Institute of Neurological Disorders and Stroke; RR, relative risk, CI, confidence interval; SITS-MOST, Safe Implementation of Thrombolysis in Stroke-Monitoring Study; TG, triglycerides. * Statistically significant at $p<0.05 .{ }^{\dagger}$ Poisson regression adjusted for age, weight, atrial fibrillation, baseline NIHSS, and dose of alteplase. 
Validation Study with adding LDL-C for Current Risk-Scoring Systems for predicting hemorrhagic transformation (ECASS II)

HAT Score

- HAT $=$ HAT (new)

SITS-SICH

- SITS-SICH $=$ SITS-SICH (new)

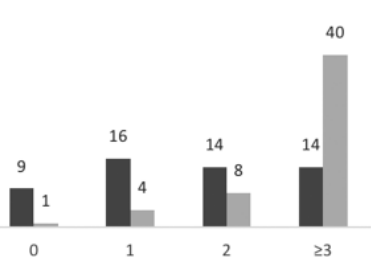

SEDAN Score

- SEDAN $=$ SEDAN (new)

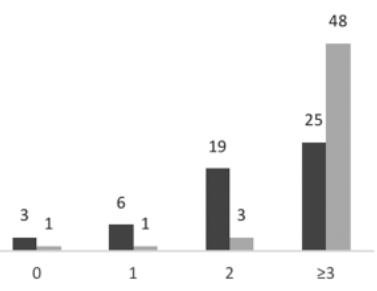

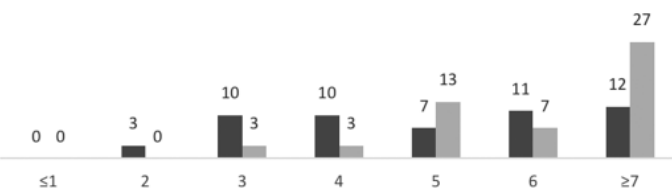

THRIVE Score

- THRIVE $=$ THRIVE (new)

\section{GRASP Score}

- GRASP1 $=$ GRASP2

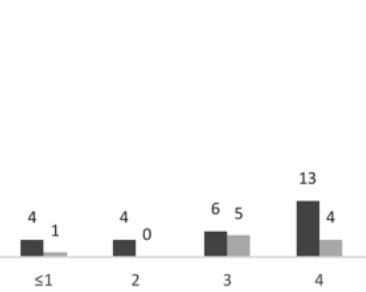

Cucchiara Score

- Cucchiara $\equiv$ Cucchiara (new)

- Horizontal Axis: the score of each risk-scoring system

- Vertical Axis: the number of patients who developed hemorrhagic transformation by the ECASS II standard

Supplemental Fig. 1. Validation Study with adding discrete LDL-C scores as the new model. All of the new models (gray bar) were more accurate in predicting SICH by the ECASS II standard.

Validation Study with adding LDL-C for Current Risk-Scoring Systems for predicting hemorrhagic transformation (SITS-MOST)

HAT score

- HAT $=$ HAT (new)
SITS-SICH score

- SITS-SICH $\mid$ ISITS-SICH (new)

\section{Cucchiara score}

- Cucchiara = Cucchiara (new)

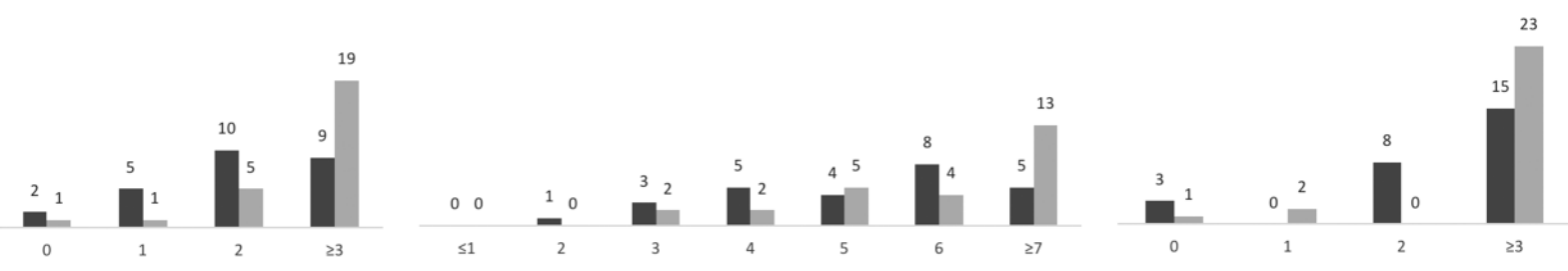

SEDAN score

- $\operatorname{SEDAN}=\operatorname{mEDAN}($ new)
THRIVE Score

- THRIVE $=$ THRIVE (new)
GRASP Score

- GRASP $=$ GRASP (new)
SPAN-100 index

- SPAN-100 $=$ SPAN-100 (new)
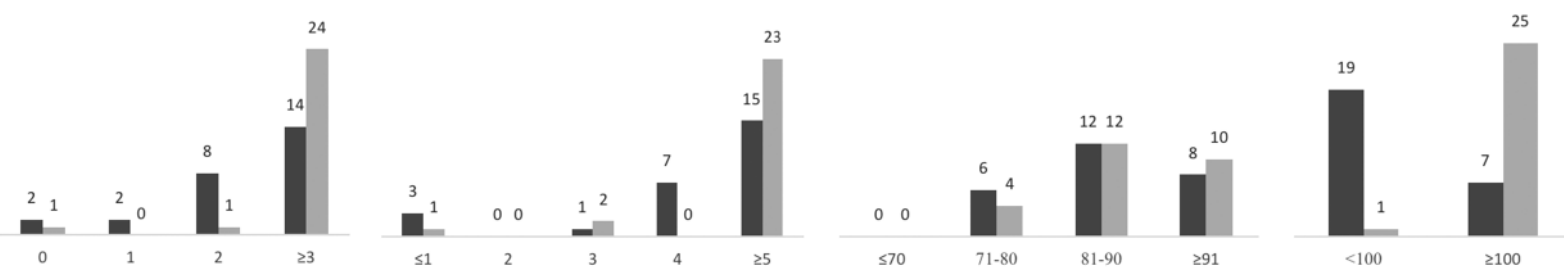

- Horizontal Axis: the score of each risk-scoring system

- Vertical Axis: the number of patients who developed hemorrhagic transformation by the SITS-MOST standard

Supplemental Fig.2. Validation Study with adding discrete LDL-C scores as the new model. All of the new models (gray bar) were more accurate in predicting SICH by the SITS-MOST standard. 


\section{Enrollment}

Assessed for eligibility in the TTT-AIS and

TTT-AIS II prospective registry $(n=2373)$

\section{Identify Patients \\ Who Were Possibly \\ Statin-naïve}

Subcohort Analysis
Excluded $(n=533)$

-incomplete data of serum total cholesterol, LDL-C, HDL-C, TG

\section{Our patient treated with intravenous thrombolysis for acute ischemic stroke had complete lipid profile $(n=1840)$}

Excluded $(n=595)$

- LDL-C of $\geq 130 \mathrm{mg} / \mathrm{dl}$ ( $n=553)$

- Total cholesterol of $\geq 200 \mathrm{mg} / \mathrm{dl}$ with two or more $\mathrm{TNHI}$ defined cardiovascular risk factors $(n=42)$

Supplemental Fig. 3. Flow diagram of subcohort identification of possibly statin-naïve patients according to the Taiwan National Health Insurance (TNHI) payment rule.

\section{References}

S1) Lou M, Safdar A, Mehdiratta M, Kumar S, Schlaug G, Caplan L, Searls D and Selim M: The HAT Score: a simple grading scale for predicting hemorrhage after thrombolysis. Neurology, 2008; 71: 1417-1423

S2) Mazya M, Egido JA, Ford GA, Lees KR, Mikulik R, Toni D, Wahlgren N, Ahmed N and Investigators S: Predicting the risk of symptomatic intracerebral hemorrhage in ischemic stroke treated with intravenous alteplase: safe Implementation of Treatments in Stroke (SITS) symptomatic intracerebral hemorrhage risk score. Stroke, 2012; 43: 1524-1531

S3) Cucchiara B, Tanne D, Levine SR, Demchuk AM and Kasner S: A risk score to predict intracranial hemorrhage after recombinant tissue plasminogen activator for acute ischemic stroke. J Stroke Cerebrovasc Dis, 2008; 17: 331-333

S4) Strbian D, Engelter S, Michel P, Meretoja A, Sekoranja L, Ahlhelm FJ, Mustanoja S, Kuzmanovic I, Sairanen T,
Forss N, Cordier M, Lyrer P, Kaste M and Tatlisumak T: Symptomatic intracranial hemorrhage after stroke thrombolysis: the SEDAN score. Ann Neurol, 2012; 71: 634641

S5) Saposnik G, Guzik AK, Reeves M, Ovbiagele B and Johnston SC: Stroke Prognostication using Age and NIH Stroke Scale: SPAN-100. Neurology, 2013; 80: 21-28

S6) Menon BK, Saver JL, Prabhakaran S, Reeves M, Liang L, Olson DM, Peterson ED, Hernandez AF, Fonarow GC, Schwamm LH and Smith EE: Risk score for intracranial hemorrhage in patients with acute ischemic stroke treated with intravenous tissue-type plasminogen activator. Stroke, 2012; 43: 2293-2299

S7) Flint AC, Faigeles BS, Cullen SP, Kamel H, Rao VA, Gupta R, Smith WS, Bath PM, Donnan GA and Collaboration V: THRIVE score predicts ischemic stroke outcomes and thrombolytic hemorrhage risk in VISTA. Stroke, 2013; 44: 3365-3369 